\title{
FLOOD EXTENT MAPPING USING DUAL-POLARIMETRIC SENTINEL-1 SYNTHETIC APERTURE RADAR IMAGERY
}

\author{
M. -J. Jo ${ }^{1}$, B. Osmanoglu ${ }^{2 *}$, B. Zhang ${ }^{3}$, S. Wdowinski ${ }^{3}$ \\ ${ }^{1}$ USRA, NASA-GSFC, Greenbelt, MD, 20771 USA - minjeong.jo@nasa.gov \\ 2 NASA-GSFC, Greenbelt, MD, 20771 USA - batuhan.osmanoglu@nasa.gov \\ ${ }^{3}$ Florida International University, Miami, FL, 33199 USA - (bzhan018, swdowins)@fiu.edu
}

Commission III, WG III/2

KEY WORDS: Flood, Polarimetry, SAR, Radar, Harvey, Sentinel-1

\begin{abstract}
:
Rapid generation of synthetic aperture radar (SAR) based flood extent maps provide valuable data in disaster response efforts thanks to the cloud penetrating ability of microwaves. We present a method using dual-polarimetric SAR imagery acquired on Sentinel-1a/b satellites. A false-colour map is generated using pre- and post- disaster imagery, allowing operators to distinguish between existing standing water pre-flooding, and recently flooded areas. The method works best in areas of standing water and provides mixed results in urban areas. A flood depth map is also estimated by using an external DEM. We will present the methodology, it's estimated accuracy as well as investigations into improving the response in urban areas.
\end{abstract}

\section{INTRODUCTION}

Floods are most common disasters for activation of International Disaster Charter according to their 2016 annual report (Bally and Papadopoulou, 2017). During 2016, 47\% of the charter activations were related to floods. Moreover, sea level rise and coastal subsidence will further increase the likelihood of flooding events in the future.

Here, we propose a simple method for rapid monitoring of flood events based on polarimetric SAR imagery. This will contribute to generating flood extent maps and estimating the flood depth. Moreover, the flood maps from the proposed method can be used for the cross-validation of those from the existing methods (Chung et al., 2015; Twele et al., 2016; Zhang et al., 2017).

\section{FLOOD MAPPING}

\subsection{Methodology}

Proposed method relies on the differences in physical interaction between standing water and the rough land surface. Due to the specular reflection over standing water the returned signal strength to the side-looking antenna is minimal in all polarizations as long as the water surface is still. On the other hand, the rough land surface has a larger signal return to the radar.

Different polarizations observed by Sentinel-1a/b also allow us to deduce more information about the land cover, as the crosspolarization channel $(\mathrm{VH})$ has a stronger return over areas with volume scattering, such as vegetated areas. Furthermore copolarization (VV) tends to have stronger returns over urban areas, due to man-made structures prominence in double bounce return. Therefore, we propose a RGB false-colour composite of pre- and post-flood data as:

$$
\begin{aligned}
& \text { R: } 20 * \log 10\left(\mid \mathrm{VV}_{\text {post }}\right) \\
& \text { G: } 20 * \log 10\left(\left|\mathrm{VH}_{\text {post }}\right|\right) \\
& \text { B: } 20 * \log 10\left(0.5 *\left(\left|\mathrm{VV}_{\text {pre }}\right|+\left|\mathrm{VH}_{\text {pre }}\right|\right)\right)
\end{aligned}
$$

Where |.| denotes absolute value, and $20 * \log 10$ is the operation to convert to $\mathrm{dB}$ scale. This composition generates an easy to interpret colour image, where existing water areas appear in black, post-event flooded areas appear in blue, and urban to rural areas vary from red to green (Figure 1).

\subsection{Estimation of Flood Depth}

The flood colour maps are useful in rapid response as they highlight the flooded areas. However, they do not provide information on the flood depth. For quantitative assessment of floods, it is possible to use an external DEM to generate flood depth maps. Figure 2 shows the processing steps of estimating flood depth. We first digitize the flooded areas from the false colour image using thresholding. This binary mask has gaps and holes, which are filled by morphological filtering operations. The disconnected flood areas are then labelled with a unique number distinguishing each connected water body. For each of these water bodies, a maximum elevation is estimated using the following equation:

$$
D E M_{\max }=\overline{D E M}+2 \sigma_{D E M}
$$

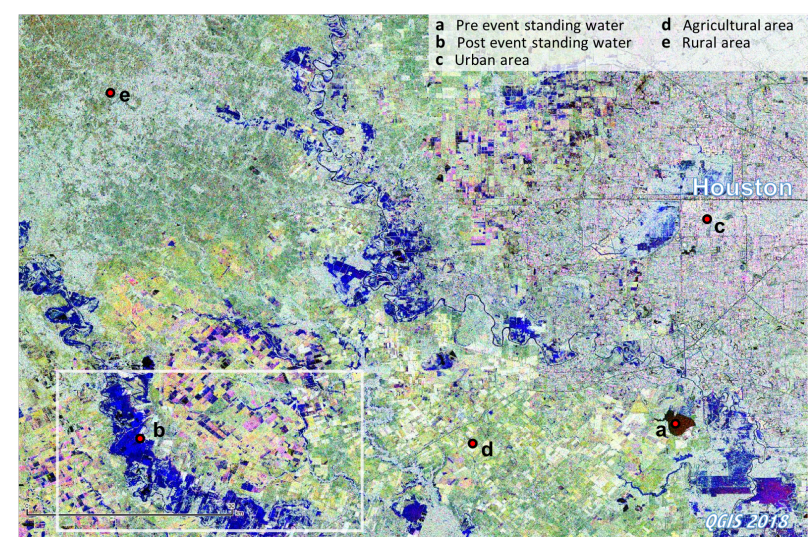

Figure 1. False colour flood map generated near Houston, TX using Sentinel-1 imagery. White rectangle shows the extent shown in Figure 3. 


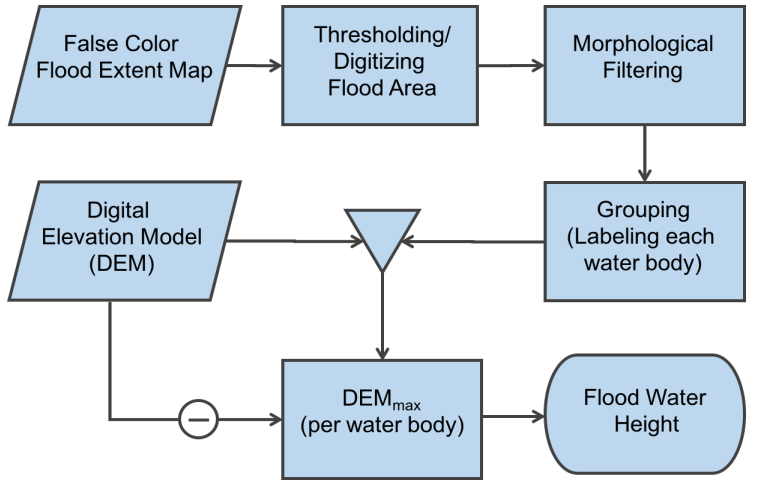

Figure 2. Flow chart for flood depth estimation

where $\overline{D E M}$ denotes mean value and $\sigma_{D E M}$ denotes standard deviation of the pixels within a water body. Then the flood depth can be estimated as:

$H_{F W D, i}=\max \left(0, D E M_{\max }-D E M_{i}\right)$

where $D E M_{i}$ is the elevation for each pixel in the connected water body, and $D E M_{\max }$ is defined for equation (2).

\section{RESULT \& DISCUSSION}

\subsection{Experiments}

We applied the proposed method for flooded areas near Houston, TX, due to the Hurricane Harvey. The pre- and post- imagery was acquired on August 18 and August 30, 2017, respectively, from the descending orbit. These imagery sufficiently covered flood periods as the heavy rainfall started on August 25.

Inundated areas were identified in blue due to the significant change of amplitude between pre- and post- imagery (Figure 1). It can be seen in Figure 3, we also generated Flood depth map using false colour image and SRTM 30m DEM.

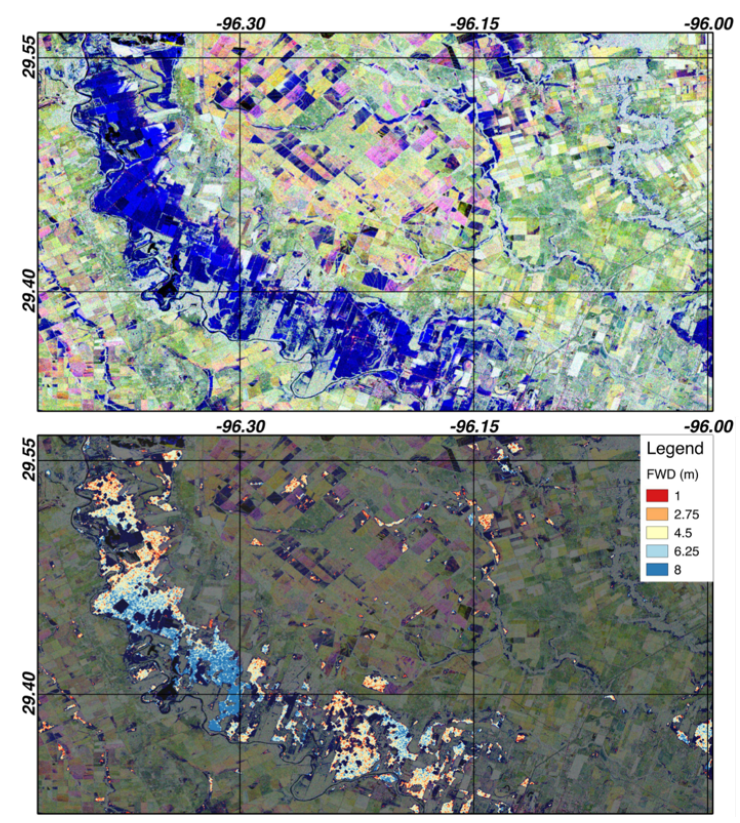

Figure 3. Flood water depth map for the area of the white rectangle in Figure 1.

\subsection{Validation}

To validate flood extent and depth maps obtained from this study, we compared our result with the flood inundation map provided from FEMA and MODIS flood map product (NRT Global Flood Mapping, 2017). FEMA map was generated to show the maximum extent of the flood water height based on NED 1/9 arcsec DEM and ground data, such as river gauges, and flood reports by FEMA response personnel (Hurricane Harvey Mitigation portfolio, 2017).

Table 1 shows the comparison results of flooded extent from each map. Two sub-areas, one rural and one urban area, were selected for the validation. By the comparison with FEMA map, we confirmed many omission errors, particularly in urban areas, though errors of commission were negligible over the entire map. The main reason of underestimation for flooded urban areas had been induced by dominant double-bounce effect. Our current method is only reliable for the areas of standing water, so different flood mapping algorithms need to be applied for the different types of land covering. Perceiving slight signal changes according to the increase of double-bounce signals when flood occurs in urban area could be one solution.

MODIS flood map showed higher agreement with our result than FEMA map. In urban areas, even though we got $99 \%$ agreement between them, most pixels were non-flooded areas. That means it was hard to detect flood from both MODIS and our product.

\begin{tabular}{|c|c|c|}
\hline \multicolumn{3}{|c|}{ FEMA Flood Map } \\
\hline & Rural (\%) & Urban (\%) \\
\hline Common Flooded/Non-flooded Area & 67.7 & 41.96 \\
\hline Only Flooded from FEMA & 30.8 & 57.99 \\
\hline Only Flooded from Sentinel-1 & 1.5 & 0.05 \\
\hline \multicolumn{3}{|c|}{ MODIS Flood Map Product } \\
\hline & Rural (\%) & Urban (\%) \\
\hline Common Flooded/Non-flooded Area & 87.4 & 99.63 \\
\hline Only Flooded from MODIS & 10.8 & 0.0 \\
\hline Only Flooded from Sentinel-1 & 1.8 & 0.37 \\
\hline
\end{tabular}

Table 1. Comparison results of flood extent against FEMA and MODIS maps

For common flooded areas, we estimated water depth difference between FEMA map and our result (Figure 4). The proposed method resulted in large underestimations in a few areas, but most pixels showed the overestimation. Mean and standard deviation of the difference was $-3.69 \pm 2.46 \mathrm{~m}$. This bias can be removed with adjustment of the standard deviation multiplier in equation (2).

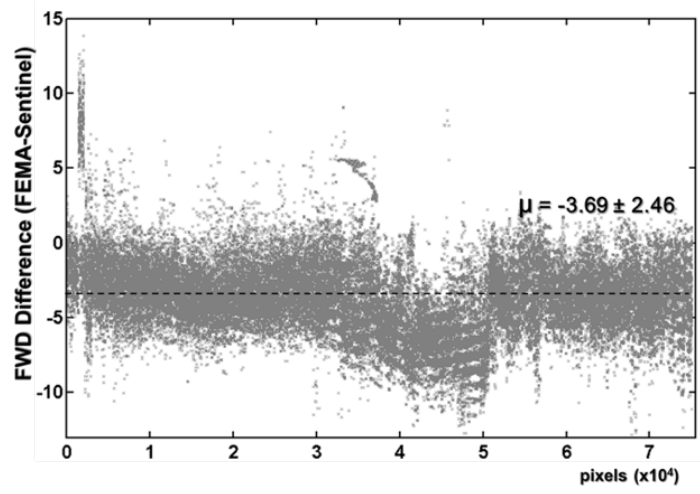

Figure 4. Flood depth difference between FEMA and Sentinel product 
High water depths in rural areas were observable in FEMA map, which were not visible in maps derived using our method or the MODIS flood extent product. We are currently collaborating with FEMA to better understand the source of this discrepancy.

\section{CONCLUSION}

We demonstrated a flood mapping technique, which results in generation of easy to interpret false-colour images as well as identifying a process-flow to estimate flood water heights. This will contribute to the rapid assessment for disaster relief efforts.

\section{ACKNOWLEDGEMENT}

This work was supported by the National Research Foundation of Korea(NRF) grant funded by the Korea government(MSIP; Ministry of Science, ICT\&Future Planning) (No. 2017R1D1A1 B03035655). The flood inundation product has been provided by the Federal Emergency Management Agency (FEMA). We also acknowledge Lori Schultz (NASA MSFC) for her assistance.

\section{REFERENCES}

Bally, P. and Papadopoulou, T., 2017. The 16th annual report: International Charter "Space and Major Disasters, pp. 17-22.

Chan, J.C.-W., Chan, K.-P., Yeh, A.G.-O., 2001. Detecting the nature of change in an urban environment: A comparison of machine learning algorithms. Photogrammetric Engineering and Remote Sensing, 67(2), pp. 213-225.

Chung, H.-W., Liu, C.-C., Cheng, I.-F., Lee, Y.-R., Shieh, M.-C., 2015. Rapid Response to a Typhoon-Induced Flood with an SAR-Derived Map of Inundated Areas: Case Study and Validation. Remote Sensing, 7, pp. 11954-11973.

FEMA GeoPlatform, 2017. Hurricane Harvey Mitigation Portfolio, fema.maps.arcgis.com (09 April 2018)

NASA Goddard's Hydrology Laboratory, 2017. Near Real Time (NRT) Global Flood Mapping MODIS Flood Water (MFW) Product, https://floodmap.modaps.eosdis.nasa.gov/ (09 April 2018)

Twele, A., Cao, W., Plank, S., Martinis, S., 2016. Sentinel-1based flood mapping: a fully automated processing chain. International Journal of Remote Sensing, 37(13), pp. 2990-3004.

Zhang, B., Koirala, R., Oliver-Cabrera, T., Wdowinski, S., Osmanoglu, B., 2017. Mapping the Extent and Magnitude of Severe Flooding Induced by Hurricanes Harvey, Irma, and Maria with Sentinel-1 SAR and InSAR Observations. American Geophysical Union Fall Meeting 2017. 